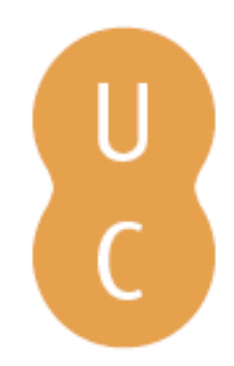

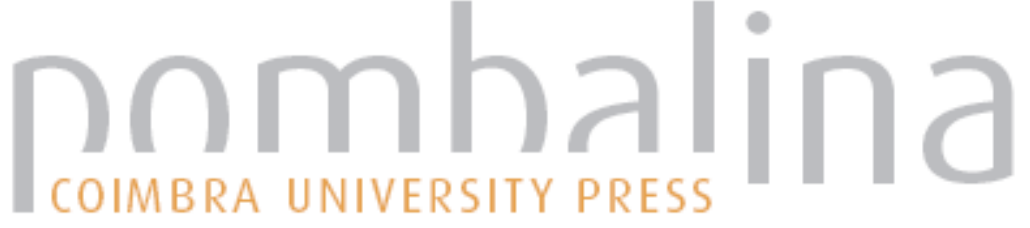

\section{Notas de um percurso académico}

Autor(es): $\quad$ Ribeiro, Maria Manuela Tavares

Publicado por: Imprensa da Universidade de Coimbra

URL

persistente: URI:http://hdl.handle.net/10316.2/47313

DOI: $\quad$ DOI:https://doi.org/10.14195/978-989-26-1849-4_22

Accessed : $\quad$ 26-Apr-2023 13:32:18

A navegação consulta e descarregamento dos títulos inseridos nas Bibliotecas Digitais UC Digitalis, UC Pombalina e UC Impactum, pressupõem a aceitação plena e sem reservas dos Termos e Condições de Uso destas Bibliotecas Digitais, disponíveis em https://digitalis.uc.pt/pt-pt/termos.

Conforme exposto nos referidos Termos e Condições de Uso, o descarregamento de títulos de acesso restrito requer uma licença válida de autorização devendo o utilizador aceder ao(s) documento(s) a partir de um endereço de IP da instituição detentora da supramencionada licença.

Ao utilizador é apenas permitido o descarregamento para uso pessoal, pelo que o emprego do(s) título(s) descarregado(s) para outro fim, designadamente comercial, carece de autorização do respetivo autor ou editor da obra.

Na medida em que todas as obras da UC Digitalis se encontram protegidas pelo Código do Direito de Autor e Direitos Conexos e demais legislação aplicável, toda a cópia, parcial ou total, deste documento, nos casos em que é legalmente admitida, deverá conter ou fazer-se acompanhar por este aviso.

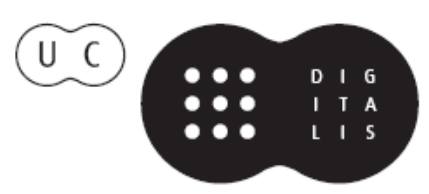


Euro-Atlântico:

Espaço de Diálogos

Isabel Maria Freitas Valente

Iranilson Buriti de Oliveira

(Coord)

\section{VISÕES \\ INTERDISCIPLINARES \\ DA EUROPA \\ E DO MUNDO:}

uma experiência de convergência

disciplinar em homenagem a

Maria Manuela Tavares Ribeiro

Alexandra Aragão

Isabel Maria Freitas Valente

Dulce Lopes

(org.)

Editora da Universidade Federal de Campina Grande

Imprensa da Universidade de Coimbra

2019 


\title{
NOTAS DE UM PERCURSO ACADÉMICO
}

\author{
Maria Manuela Tavares Ribeiro
}

Procurei fazer o meu caminho ao longo de 45 anos de serviço na Faculdade de Letras da Universidade de Coimbra, como Docente e como Investigadora, que continuo a ser na comunhão de saberes, de experiências, de vivências, de convivialidade.

Iniciei a minha carreira com a sábia orientação do meu Mestre, Professor José Sebastião da Silva Dias, que recordo com sentida gratidão, em 1971. Com ele colaborei no Seminário de Cultura Portuguesa, com ele trilhei o percurso de aprendiz de Investigadora. Incutiu-me o gosto pela investigação, pela análise das fontes, pela procura da metodologia adequada a cada estudo, sempre com sentido de rigor. Já em 1969, na disciplina do Seminário, que culminava o último ano da Licenciatura (de 5 anos), iniciou os seus discípulos nos estudos sobre as temáticas do século XIX. Abriram-se-me novas perspectivas. Estimulava-me a proceder a análises comparativas e a cruzar abordagens no campo da História, do Direito, da Sociologia, da Economia, da Literatura. Foi assim que ultimei a Tese de Licenciatura sobre António Pedro Lopes de Mendonça, Vida e Obra - o pensamento dos socialistas utópicos de meados de Oitocentos, em 1974. Interessou-me, desde logo, analisar as ideias de Europa dos intelectuais portugueses, muitos deles, formados em Direito, na Universidade de Coimbra, outros na Escola Politécnica de Lisboa. Análise esta que pressupôs um estudo aprofundado da conjuntura nacional - política, social, económica, cultural e da conjuntura europeia.

Tornou-se imprescindível a apreensão dos ideais de pensadores europeus que reflectiram sobre os movimentos políticos, sociais e culturais europeus. Estes estudos comparativos foram fundamentais. Como a interpelação entre a análise de carácter histórico, social, cultural que me conduzia a cruzar a História, o Direito, a Literatura, a Cultura, as Relações Internacionais, a diplomacia era essencial. Assim procurei fazer na minha tese de Doutoramento, defendida em 1988, 
sobre Portugal e a Revolução de 1848.

Prosseguia a minha carreira de Investigadora no Centro de História da Sociedade e da Cultura, como um dos membros fundadores, bem como o Instituto de História e Teoria das Ideias, ambos criados em 1976, sob a direcção do Professor Silva Dias. Foram múltiplas as actividades institucionais, quer na minha carreira individual, quer a nível colectivo. Foram anos de cumplicidade intelectual e académica com o Professor Silva Dias e distintos Colegas, que muito contribuíram para a minha formação científica, pedagógica e humana. Sou-lhes muito grata. O seu inestimável apoio manifestou-se também quando, já então na Carreira Docente, em 1988, assumi funções directivas no Centro de História da Sociedade e da Cultura, no Instituto de História e Teoria das Ideias, na Direcção da Revista de História das Ideias e como Coordenadora de alguns dos seus números, na Comissão Científica do Grupo de História (1993-1994).

Foram tempos úteis de aprendizagem e de cooperação interuniversitária, a nível nacional e internacional. Recordo que a partir de 1993, como membro de um Programa Erasmus tive o privilégio de integrar um grupo de reconhecidos Professores da área de História, Direito, Relações Internacionais, Estudos Europeus, entre eles Ariane Landuyt, Coordenadora do Master in European Studies, com sede na Universidade de Siena. Foram muitos anos de profícuo trabalho colectivo: cursos intensivos, colóquios, seminários, publicações. Um dos princípios norteadores desse trabalho científico - a interdisciplinaridade, tão exigente quanto enriquecedora, traduziu-se nas nossas carreiras individuais e no aproveitamento sentido pelos participantes, estudantes Erasmus, que circulavam então entre as Universidades de Coimbra, Salamanca, Granada, Poitiers, Estrasburgo, Siena. Pequeno, mas forte grupo de Professores que se foi ampliando.

Na minha Faculdade de Letras da UC ensinava Cultura Portuguesa, História Contemporânea, História Contemporânea de Portugal e, a partir de 1998, quando fiz a Agregação, dinamizei o ensino, em Seminários, de várias disciplinas no âmbito dos Estudos Europeus. Foi então que inaugurei o Mestrado Europa - as Visões do "Outro", na FLUC, depois 
da criação da Licenciatura em Estudos Europeus, no âmbito de uma Faculdade de Humanidades. Havia, como sabemos, os Estudos Europeus nas Faculdades de Direito e de Economia.

Foi um labor intensíssimo a nível da FLUC, pois a Comissão responsável, a que presidi durante dois anos, era integrada por representantes de todos os Institutos (ainda não eram Departamentos) da Faculdade. Trabalho aturado, mas gratificante. Uma preocupação basilar - a interdisciplinaridade, a análise comparatista - nacional e internacional.

Quando as ciências se cruzam, o fascínio da descoberta torna-se ainda maior. Do cruzamento interdisciplinar a ciência beneficia. Já em 1971, Vitorino Magalhães Godinho afirmava: "a história tem de ser, no seu cerne, economia política, sociologia, geografia, sociologia", etc. Da interdisciplinaridade passa-se a um grau mais elevado de modo a alcançar a transdisciplinaridade na qual "através de uma certa aglutinação científico-metodológica, cada problema, cada questão é vista, é analisada, é problematizada sob todos os ângulos possíveis".

No domínio dos Estudos Europeus a que me fui dedicando, verifiquei, desde logo, que eles tinham necessariamente de assumir uma dimensão interdisciplinar para que os Estudos Europeus sejam, de facto, uma confluência de diversas disciplinas que estudam várias áreas. Já afirmei num texto, dado a público em 2003, que o tema Europa constitui um "objecto de estudo" no âmbito das ciências humanas e sociais em geral (A ideia de Europa - uma perspectiva histórica). Ela foi, desde sempre, plural. E é essa matriz plural, é essa multiplicidade e diversidade que devem ser sopesadas quando se questiona, discute e reflecte sobre a história, o direito, a filosofia, a geografia, a política, a economia, a religião, as culturas, a cidadania, as identidades, as relações internacionais, a ciência.

Assim se procurou fazer no âmbito do Mestrado Europa - as Visões do "Outro", no Mestrado em História Contemporânea, no Curso de Doutoramento de Altos Estudos Contemporâneos (História Contemporânea e Estudos Internacionais Comparativos) a funcionar em 2005, na Licenciatura em Jornalismo, na Licenciatura de Estudos 
Europeus (2004), no 2. ${ }^{\circ}$ Ciclo de Estudos Europeus e no Curso de Doutoramento de Estudos Europeus, na FLUC, cuja criação eu própria apresentei à FLUC.

$\mathrm{Na}$ carreira docente, foram muitas as disciplinas que regi no âmbito destes cursos. Em simultâneo, exerci serviço docente em outras Universidades, nacionais e estrangeiras, como Professora Visitante. Sublinho a importância do já referido Master in European Studies, coordenado pela Prof. ${ }^{a}$ Ariane Landuyt da Universidade de Siena. O grupo do antigo Programa Erasmus foi sucessivamente largado até à extinção do referido Master, há poucos anos, quando integrava já dezasseis Universidades. Foram muitos os estudantes de várias nacionalidades, europeus e extra-europeus, que frequentaram o Master e muitas as dissertações concluídas.

Uma experiência riquíssima, a nível da docência, da investigação, das relações humanas criadas com os Colegas e com os discípulos. Várias publicações colectivas foram dadas a público, diversos colóquios, seminários, jornadas e cursos intensivos tiveram lugar, muitos deles com o alto patrocínio da Comissão Europeia.

A minha investigação prosseguia. A partir de 1998, integrei o Centro de Estudos Interdisciplinares do Século XX da Universidade de Coimbra - CEIS20 - fundado pelo meu Colega e Amigo Luís Reis Torgal, com a colaboração de seis Colegas. Criei, então, um dos Grupos de Investigação com 4 Linhas de Acção, hoje designado Europeísmo, Atlanticidade e Mundialização, que coordenei até Janeiro de 2018. O Grupo centra a sua investigação em 4 áreas temáticas: Portugal e a Europa; Europa das Regiões e as Relações Transatlânticas; Fronteiras, Democracia, Direitos Humanos e Governança e Sustentabilidade. Procura-se inteligir as relações internacionais de Portugal com a Europa, mas alargam-se os horizontes de investigação, analisando as relações com países africanos, americanos (da América do Norte e do Sul) nos séculos XIX-XXI. Cruzam-se nos estudos publicados, nas teses de mestrado e de doutoramento, nos projectos, perspectivas históricas, jurídicas, filosóficas, geográficas, religiosas, culturais e de ciência política e relações internacionais no quadro de uma problematização 
trans e interdisciplinar. Desenvolvem-se os estudos comparativos; privilegia-se a dimensão à escala internacional pela mobilidade dos investigadores, a permanente articulação entre reflexão teórica e dados empíricos; procura-se responder pelo debate crítico, científico e cultural às solicitações da comunidade científica e geral. A nível deste Grupo de Investigação têm-se intensificado as relações com várias Universidades, Centros de Investigação, Instituições Comunitárias europeias, Fundações nacionais e estrangeiras, na Europa, na outra margem do Atlântico e com uma projecção mundial.

Procura-se a interacção com outros Grupos do CEIS20. Estabelecemse parcerias mediante acordos e protocolos que envolvam também a sociedade civil em iniciativas conjuntas. Tudo isto resulta de um trabalho colectivo dos Investigadores Integrados e Colaboradores do Grupo. A sua participação tem sido notável, quer nas publicações em livros e em artigos em revistas com arbitragem científica, quer em projectos, em redes internacionais, quer em teses de mestrado e de doutoramento concluídas, em projectos de pós-doutoramento, no contributo empenhado e relevante do Curso de Doutoramento em Estudos Contemporâneos, cuja proposta de criação apresentei no âmbito do CEIS20, em 2011. De natureza interdisciplinar, ela tem-se revelado um dos pilares fortes do CEIS20, um dos seus rostos que lhe dá visibilidade, profundamente ancorado nos desafios emergentes da contemporaneidade. Enquanto fui sua Directora contei sempre com a colaboração de muitos membros do CEIS20, dos seus Subdirectores João Rui Pita e João Paulo Avelãs Nunes e do inexcedível apoio do Instituto de Investigação Interdisciplinar. Registe-se ainda a colaboração na Revista de Estudos do Século XX criada pelo Doutor Reis Torgal, como Coordenadora e Autora. Refira-se também a importância da revista Debater a Europa, de que sou Directora, com o notável empenho e sempre atenta colaboração da Doutora Isabel Valente, que conta já com 21 números, respeitando uma periodicidade regular e com a chancela da Imprensa da Universidade.

Mas se coordenei este Grupo de Investigação, ele é fruto e espelho do trabalho, do empenho, do interesse, da produção científica dos seus 
membros, bem demonstrado nos Relatórios anuais e quinquenais. Tem havido uma preocupação que interessa registar - a de articular os contributos científicos do Grupo com os dois Programas de Investigação do CEIS20.

A orientação de muitas teses de mestrado e de doutoramento e de bolseiros pós-doc deu-me uma contínua vontade de actualização científica, um gosto imenso de ver jovens investigadores tão interessados num trabalho de pesquisa insistente, de labor em arquivos e bibliotecas cujo interesse, penso, lhes consegui transmitir, quer no empenho de renovação metodológica, quer em abordagens inovadoras. Com eles muito aprendi.

A minha carreira muito deve a muitas dezenas de estudantes, mas muito deve aos meus discípulos, orientandos, alguns deles membros do CEIS20, sempre colaborantes. Estou-lhes grata.

A extensão dos Estudos Europeus nos Estudos Euro-Atlânticos, fezse na Universidade dos Açores com o entusiasmo e mérito dos Doutores Carlos Amaral, Berta Pimentel, como aconteceu com a ligação estreita à Universidade de Oradea. Dei, com interesse, todo o meu modesto contributo.

Assim o fiz como Coordenadora Científica do CEIS20, como Directora da Revista Estudos do Século XX e Debater a Europa, como Coordenadora da Colecção História Contemporânea, que se publica desde 2009, com a chancela da Imprensa da Universidade, e da Colecção Estudos sobre a Europa, iniciada também em 2009, com a chancela da Editora Almedina. Sempre tive o apoio colaborante dos Coordenadores Científicos Luís Reis Torgal, António Pedro Pita e António Rochette, de muitos Investigadores, dos Coordenadores dos Grupos e das Colaboradoras do CEIS20.

Foi estimulante participar na elaboração dos Estatutos do Instituto de Investigação Interdisciplinar, cuja Comissão era coordenada pelo seu Director de então, Doutor António Gomes Martins. Muitos meses de trabalho persistente, mas frutuoso. Louvo a iniciativa, porque hoje temos esta nossa Unidade Orgânica, com prestígio e com uma dinâmica assinalável, que pude acompanhar durante anos numa estreita e frutuosa 
interacção entre o III e o CEIS20.

O CEIS20, a Faculdade de Letras, em suma, a Universidade de Coimbra, possibilitaram-me também, ao longo dos anos uma desejável e imprescindível internacionalização. Foram muitos os encontros científicos em que participei, que tanto enriqueceram a minha carreira académica e a minha formação como Investigadora, como Docente, como Cidadã. Pude conhecer tantas outras instituições universitárias, onde colhi uma contínua aprendizagem científica, cultural e

estimulantes relações humanas que continuo, muitas delas, a acarinhar.

Encontrei também nas sociedades científicas, de que sou membro, caloroso acolhimento: na Academia Portuguesa da História, na Academia das Ciências de Lisboa, na Academia Internacional de Cultura Portuguesa, na ICRHPI, entre outras. As suas sessões semanais e comgressos são bons momentos de reflexão e de debate. A minha participação em Conselhos Editoriais e em Comissões científicas de revistas nacionais e estrangeiras permitem-me a leitura de muitos textos que versam temas nas áreas em que continuo a trabalhar: história das ideias e da cultura; Intelectuais e ideias de Europa; Pacifismo e Internacionalismo; Federalismo; o processo de construção e de integração europeia; Relações internacionais; Diplomacia, Política e Instituições; Identidades. Sobre muitos desses temas produzi livros, artigos, recensões críticas e organizei muitos Encontros Científicos, em Portugal e no estrangeiro, sempre colaborante e participante, e com denodado interesse e curiosidade científica, que procuro manter.

É reconfortante e confesso o meu sentido orgulho em partilhar este Colóquio de hoje que tomo como um gesto tão generoso. Agradeço com sentida gratidão. Às Caras Amigas Organizadoras, Doutoras Alexandra Aragão, Isabel Maria Freitas Valente, Dulce Lopes, um Bem Hajam muito sentido. Mas deixem-me partilhar este gesto com todos os que deram o seu melhor contributo ao nosso Grupo de Investigação, os que estão presentes e outros que, por razões imperiosas, não puderam participar de viva voz. Apraz-me sublinhar o interesse e a oportunidade do tema do Colóquio. Felicito-as. O meu renovado Obrigada. 
Este Encontro será marcado, creio bem, pelo discurso analítico, interrogante e crítico dos historiadores, dos filósofos, dos juristas, de geógrafos, dos especialistas em Estudos Europeus e em Relações Internacionais. São essas vossas visões inovadoras, em perspectiva comparada e interdisciplinar, que enriquecem cada um de nós, todos nós, o nosso Grupo, o CEIS20, a Universidade de Coimbra.

Aos Coordenadores do Grupo, Doutores Carlos Eduardo Pacheco Amaral e Isabel Maria Freitas Valente, o meu justo reconhecimento. Podem contar com a minha colaboração e formulo votos sinceros de todo o sucesso e êxito para o nosso Grupo de Investigação.

Ao Coordenador Científico do CEIS20, o meu obrigada. Aos Colegas, aos meus discípulos, a todos vós, com quem muito aprendi, e aprendo, o meu testemunho de profunda estima e de incontida gratidão. 